Journal of Engineering and Applied Sciences 14 (Special Issue 7): 10207-10215, 2019

ISSN: 1816-949X

(C) Medwell Journals, 2019

\title{
Analysis of Impacting Wave using Piezoelectric Sensor for a Pressurized Thin Aluminum Plate Covered with a Composite Material
}

\author{
Ali Kamil Jebur \\ Department of Electromechanical Engineering, University of Technology, \\ Baghdad, Iraq
}

\begin{abstract}
A circular thin aluminum plate is coated by a composite material from a wood/polypropylene, made from a different wood flour percentage weight (25,50 and $75 \%)$ and grain size (50,100 and $150 \mu \mathrm{m})$, a constant internal pressure is subjected below the thin aluminum plate and impacted in upper coated surface with a different weight of a stainless steel ball which is freely dropped. The Light Dependent Resistor (LDR) Arduino sensor system, digital dial gage and piezoelectric sensor are used and controlled by an Arduino hardware and software for measuring and recording the vibrating data for analyzing the response vibrated signal after impact. The vibration signal analysis shows the increasing of the damping ratio 0.085-0.35 after the free drop impact and a decreasing in impacted time during increasing in weight of impacted load with type of wood grain size $150 \mu \mathrm{m}$ and with a wood flour $75 \mathrm{wt} . \%$ in the raise. The deformation results are nearly agree with the Roark's formulas, more than using mindlin plate theory which help to understand the vibration behavior of this composite material under a free drop impact test and to make a suitable shock absorber layers.
\end{abstract}

Key words: Composite material, impact, piezoelectric sensor with arduino hardware, vibration control, LDR, mindlin plate

\section{INTRODUCTION}

Polypropylene is used as polymer matrix with a reinforcing filler like liquefied tropical wood to made Liquefied Tropical Wood/Polypropylene composites (LTW/PP), under tensile test the composites were evaluated and it seems to be that the modulus of elasticity is increased due to the addition of these filler Liquefied Tropical Wood (LTW) in the composites which is prepared with 10, 20, 30 and $40 \mathrm{wt} . \%$ (Idrus et al., 2011). In Polypropylene (PP) it can be reinforced with wood flour $0,5,10$ and $20 \mathrm{wt} . \%$ to increase stiffness and impact resistance which does not have a large change as a function of wood content and at large wood content the stiffness is increasing and led to a small fracture toughness with micromechanical deformation processes and the deformation processes, generally, depend on the strength of polypropylene/wood interaction. in the wood contents range (50-60 wt.\%), the large impact resistance cannot be prepared in composite (Keledi et al., 2012).

Because of the powder particles used in composite material which may represent points for a localized stress concentration from which the failure will begin. Under impact test, the impact strength decreases with increasing of powder particles weight fraction and for the all groups investigated of composite materials compared to the impact strength of the matrix, all of these results have been reported mainly due to the reduction of elasticity of material due to powder addition and thereby reducing the deformability of matrix and in turn the ductility in the skin area (Mohammed, 2015). The impact strength of A16061/SiC metal matrix composites reinforced with nanoparticles of weight percentage (3, 6, 9 and $12 \%$ ) was studied. The improvement of impact strength was observed with increasing the weight percentage of $\mathrm{SiC}$ nanoparticles. The maximum strength is showed with the 12 wt. \% nano $\mathrm{SiCp}$ aluminum composites. It is seen that the impact energy of the composites increase gradually with filler content increasing from 3-12 wt.\% (Mohammed and Hanoos, 2017). With mechanical testing of material like impact test is one of the test used to test mechanical properties of composites and the Charpy impact is one of impact type method. As a filler material in composites like a wood flour is used to made a material with more rigid and brittle but due to the water absorption and swelling the strength is decreased and the impact strength is increased (Kallakas et al., 2015). The impulsive forces as being forces of very large magnitude that act over a very small interval of time but cause a significant change in the momentum. Impulsive forces are those generated when a steel ball hit a metallic aluminum plate (with and without coating), typical time intervals of impulses occur during the impact start from 0.18-0.2 msec for steel impacted test (Young and Budynas, 2002; 
Peraire and Widnall, 2003). Piezoelectric sensor is used in experiments with an error between 3.0 and $7.5 \%$ error in the experimental frequencies which is lower than the analytical solution using vibrational equations for the aluminum plate shaker testing and the dynamics parameters of composites plate with the bending modal frequencies are solved by Euler theory which predicts tends to be about $5 \%$ larger than experimental results in deflection for any amplitude and frequency in plate testing with the Ritz assumption mode method for analytical solution for the effective of damping ratio as a ratio of energy absorbed to total system energy which predicts linear piezoelectric effects (Tremaine, 2012). Polystyrene, low density polyethylene, polypropylene and poly methacrylate are the polymer materials which are investigated under the impact test and performed at room temperature according to ISO 179 each sample was tested for 3 times and average results have been reported and represented that the increasing of PP content in polymer makes the impact properties and fracture toughness increases for blends system (Salih et al., 2015).

The aim of this research is to study the effect of the wood flour percentage weight in wood/polypropylene composite material on the response of vibrated signal generated due to the impact test. This results measured by a digital dial gage and a piezoelectric sensor which are controlled by an Arduino hardware and software.

Mathematical equations: For free drop impacting bodies, it is necessary to calculate the parameters requirements velocity, acceleration just before impact and the impacted force just before impact. These set of equations are used for impacting contacted time $\tau_{\text {pulse }}=$ 0.0005-0.02 for different material (Metz, 2007):

$$
v=\sqrt{2 \mathrm{gh}} ; \quad \mathrm{a}=\frac{\sqrt{8 \mathrm{gh}}}{\mathrm{t}_{\text {pulse }}} ; \quad \mathrm{F}=\mathrm{ma}=\frac{\mathrm{w}}{\mathrm{g}} \times \mathrm{a}
$$

Using Roark's formulas, the maximum stress under static load is (Young and Budynas, 2002):

$$
\sigma_{\text {max }- \text { sta }}=\left[\frac{\mathrm{F}}{\mathrm{t}^{2}}(1+\mathrm{v})\right]\left[0.485 \text { in }\left(\frac{\mathrm{D}}{2 \mathrm{t}}\right)+0.52\right]
$$

And the static maximum deflection at the center of the circular plate using Roark's formulas:

$$
\delta_{\max -\mathrm{sta}-\mathrm{R}}=\frac{0.05425 \mathrm{FD}^{2}}{\mathrm{Et}^{3}}
$$

For using thin plate in tank vessel by using Mindlin's plate theory for thin circular plate which is Clamped $360^{\circ}$ and a uniformly distributed load is subjected, the maximum elastic deflection and stresses are calculated by Gujar and Ladhane (2015). $\mathrm{D}_{\mathrm{r}}$ : flexural rigidity of the plate which can be calculated as follows:

$$
D_{r}=\frac{E t^{3}}{12\left(1-v^{2}\right)}
$$

By using Mindlin's plate theory for thin circular plate which is Clamped $360^{\circ}$ and a concentrated load is subjected, the maximum elastic deflection and stresses are calculated by Gujar and Ladhane (2015):

$$
\sigma_{\mathrm{r}-\max }=-\frac{3 \mathrm{P}}{2 \pi \mathrm{t}^{2}} ; \sigma_{\theta-\max }=-\frac{3 \mathrm{vP}}{2 \pi \mathrm{t}^{2}}
$$

For $\sigma_{\theta-\max }<\sigma_{\mathrm{r}-\max }$; then the study should take maximum stress for load safety during calculations to avoid the failure of the material:

$$
\delta_{\max -\mathrm{sta}-\mathrm{M}}=-\frac{\mathrm{Pr}^{2}}{16 \pi \mathrm{D}_{\mathrm{r}}}
$$

Roark and mindlin formulas: In composite materials it is necessary to change the modulus of elasticity in Eq. 4 which is represented the equivalent modulus of elasticity when determine the properties of a composite laminate for each component the volume fractions should be known and calculated using the rule of mixtures as shown in Eq. 7 (Gibson, 2011):

$$
\mathrm{E}_{\mathrm{c}}=\mathrm{E}_{1} \mathrm{~V}_{1}+\mathrm{E}_{2} \mathrm{~V}_{2}
$$

Where:

$\mathrm{E}_{\mathrm{c}}=$ The composite modulus of Elasticity

$E_{1,2}=$ The modulus of Elasticity for first and second material

$\mathrm{V}_{1,2}=$ The Volume fraction for first and second material

After impact it seems that the plate continue vibrated with a ununiformed wave until stop vibrate which different from impact to another due to the different type of composite materials which dependent on the $\mathrm{w} \%$ of the wood flour, so, it is necessary to start from the equations of motion after impact can easily be put in the classical matrix as (Anonymous, 2016):

$$
M \ddot{x}+C \dot{x}+K x=F(t)
$$


For the damping value can be estimated approximately by measuring the logarithmic decrement of each mode separately and through a band-pass filter centered at the particular frequency of interest, it can solved experimentally by filtering the system response signal for better estimation of damping and this methods is recommended. Logarithmic decrement is defined as the natural logarithm of the ratio of any two consecutive amplitudes in the time domain (Anonymous, 2016):

$$
\begin{gathered}
\delta=\zeta \omega_{\mathrm{n}} \mathrm{T}_{\mathrm{d}}=\delta=\frac{\ln \mathrm{x}_{1}}{\mathrm{x}_{2}}=\frac{2 \pi \mathrm{T}_{\mathrm{d}}}{\sqrt{1-\zeta^{2}}} \\
\omega_{\mathrm{d}}=\omega_{\mathrm{n}} \sqrt{1-\zeta^{2}} \\
\mathrm{~T}_{\mathrm{d}}=\frac{2 \pi}{\omega_{\mathrm{d}}}=\frac{2 \pi}{\sqrt{1-\zeta^{2}}} \frac{1}{\omega_{\mathrm{n}}}
\end{gathered}
$$

Where:

$\zeta=$ The damping ratio

$\omega_{\mathrm{n}}=$ The natural frequency

$\mathrm{T}_{\mathrm{d}}=$ The damping period

Critical damping ratios for the first 10 or so, modes range from $0.04-0.8 \%$. For the stiffened plate, it varies from $0.05-2 \%$ even though aluminum is used throughout by using the logarithmic decrement is dimensionless from the dimensionless damping ratio $\zeta$ by the displacements $\delta$ resulted and measured theoretically and experimentally (Bakir, 2004):

$$
\zeta=\frac{\delta}{\sqrt{4 \pi^{2}+\delta^{2}}}, \text { where } \delta=\ln \frac{\mathrm{x}_{1}}{\mathrm{x}_{2}}
$$

The measuring of the natural frequency and damping coefficient for a mode of component vibration can be measured by the force vibration response of the impacted system by measuring the bandwidth $\Delta \omega$ and the maximum amplitude like the logarithmic decrement which gave the forced harmonic response as a measure of the damping in system with taken in the consideration that the maximum, measured by apply in Eq. 13 and 14 (Chauhan et al., 2009; Verros et al., 2005):

$$
\begin{gathered}
\zeta=\frac{\Delta \omega}{2 * \omega_{\text {max }}} \\
\mathrm{c}=2 \mathrm{~m} \omega_{\mathrm{n}} \zeta
\end{gathered}
$$

\begin{tabular}{|c|c|}
\hline Elements & Composition $(\%)$ \\
\hline$\overline{\text { Magnesium (Mg) }}$ & $4.0-4.90$ \\
\hline Manganese (Mn) & $0.40-1.00$ \\
\hline Iron $(\mathrm{Fe})$ & 0.40 \\
\hline Silicon (Si) & $0.0-0.40$ \\
\hline Titanium (Ti) & $0.05-0.25$ \\
\hline Chromium $(\mathrm{Cr})$ & $0.05-0.25$ \\
\hline Copper $(\mathrm{Cu})$ & 0.10 \\
\hline $\operatorname{Zinc}(\mathrm{Zn})$ & $0.0-0.10$ \\
\hline Aluminium $(\mathrm{Al})$ & Balance \\
\hline Properties & Values \\
\hline Proof stress $(\mathrm{MPa})$ & 110 \\
\hline Ultimate strength $(\mathrm{MPa})$ & 250 \\
\hline Density $\left(\mathrm{kg} / \mathrm{m}^{3}\right)$ & 2650 \\
\hline Hardness Brinell (HB) & 73 \\
\hline Modulus of elasticity (GPa) & 70 \\
\hline Passion ratio & 0.39 \\
\hline
\end{tabular}

\section{MATERIALS AND METHODS}

\section{Experimental materials analysis}

Material preparation: According to the procedures in ASTM standards D 638 and D 790 for tensile tests and
Table 1: Chemical composition for aluminum plate used

Table 3: Mechanical properties of polypropylene used

\begin{tabular}{ll}
\hline Properties & Values \\
\hline Tensile strength $(\mathrm{MPa})$ & 25 \\
Density $\left(\mathrm{kg} / \mathrm{m}^{3}\right)$ & 905 \\
Elongation at break $(\%)$ & 150 \\
modulus of elasticity $(\mathrm{GPa})$ & $1-1.4$ \\
Notched izod impact $(\mathrm{kJ} / \mathrm{m})$ & 0.07 \\
Rockwell "R" scale & 80 \\
\hline
\end{tabular}

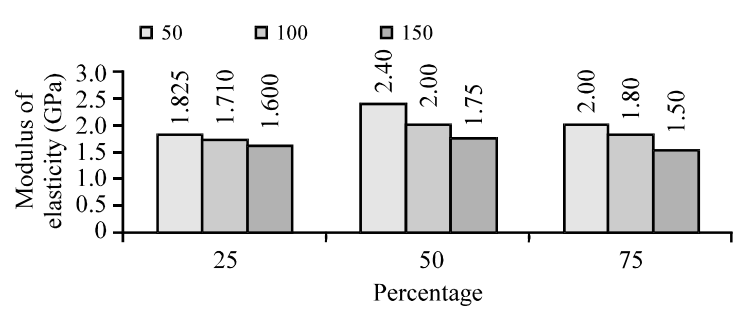

Fig. 1: Comparison between three grain sizes (50, $100,150 \mu \mathrm{m})$ of flour wood with a three deferent percentage weight $(25,50,75$ wt.\%) in polypropylene as a matrix

Izod impact strength were measured by Instron impact pendulum tester under ASTM D 256 with notched specimens depth $=2 \mathrm{~mm}$ at $50 \%$ relative humidity and room temperature at $24^{\circ} \mathrm{C}$ (Fig. 1).

To understand the type of material testing, it needs to analysis the tested metal pleat, especially, chemical composition and the mechanical properties as shown in Table 1-3, respectively.

From Table 1 and the recognition of this plate is an aluminium alloy 5086 and the experimental mechanical properties for aluminium alloy is tested as in Table 2. From the standard in which describe the properties of the polypropylene used as a matrix and these values are near to the minimum values in the commercial polypropylene production used the properties of polypropylene is a (Semi-rigid, Translucent, Good chemical resistance, 


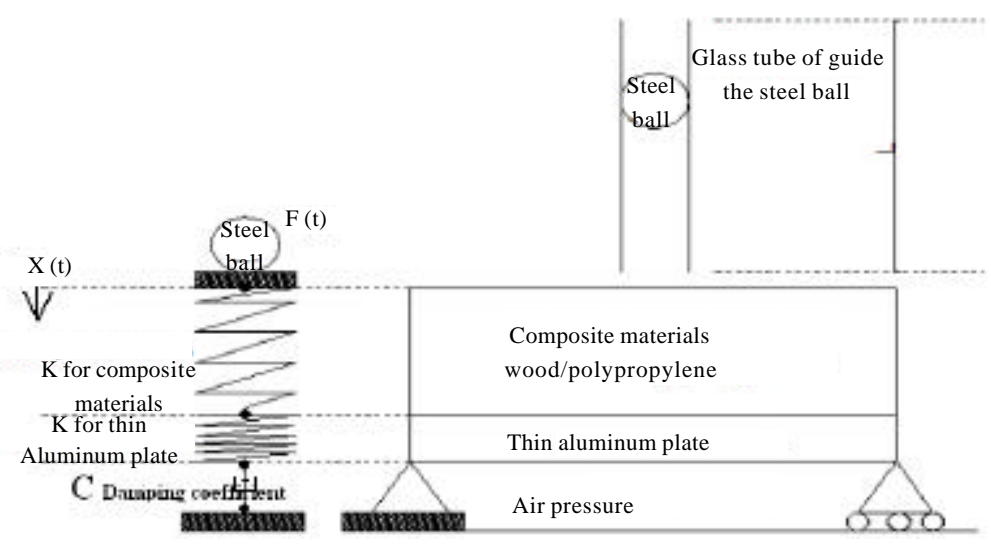

Fig. 2: Testing scheme process as consideration SDOF under impact test

(a)

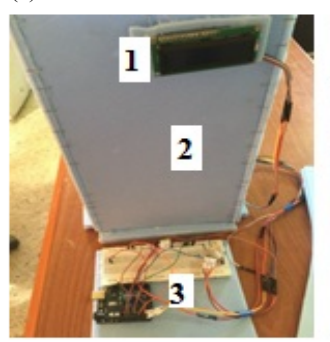

(b)

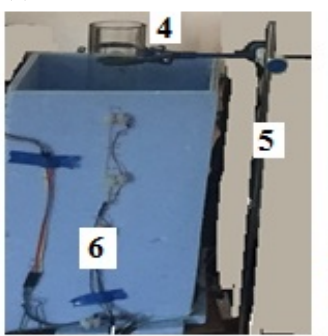

(c)

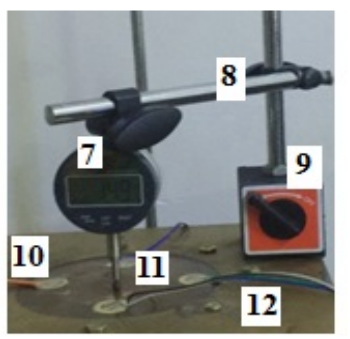

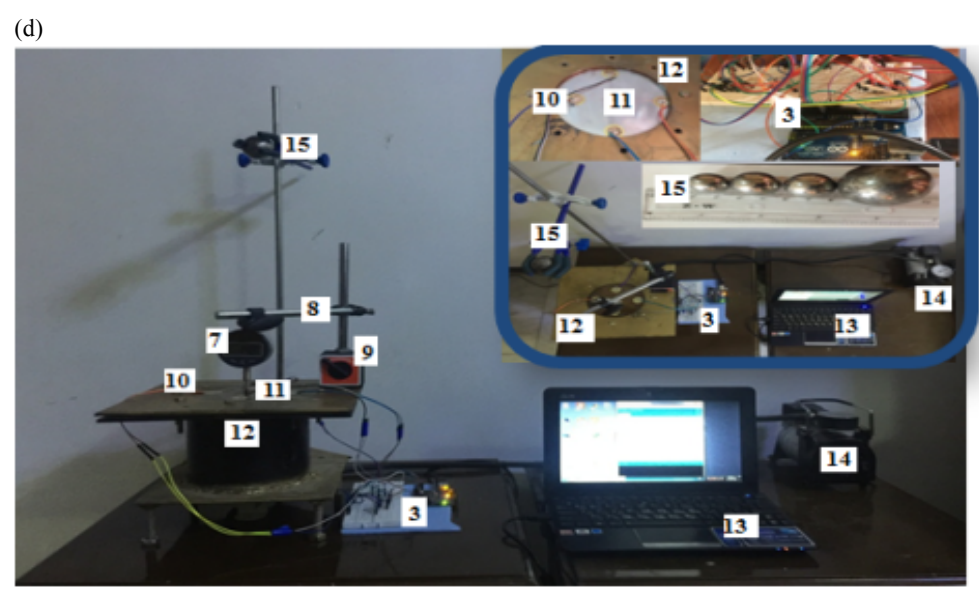

Fig. 3: a-d) Computational experimental equipment with electrical measuring equipments: 1) The LCD monitor; 2) The duct for covering the test; 3 ) The Arduino hardware with connectors wires; 4) The frictionless tube for vertical direction path of impactor; 5) The supporters; 6) The LDR sensors; 7) The Digital Dial Gage (DDG); 8) The supporter of the Digital Dial Gage (DDG); 9) The magnetic supporter for the Digital Dial Gage (DDG); 10) The piezoelectric sensor; 11) The pressurized thin aluminum plate; 12) The steel base container for air pressure and supporters; 13) The computer interface for data recording; 14) The compressor for air pressure supply and 15) The steel ball for free drop test

Tough, Good fatigue resistance, Integral hinge property, Good heat resistance) and as shown in Table 3 . Three type grain size 50, 100, $150 \mu \mathrm{m}$ of wood flour are mixed with a deferent percentage weight
(25, 50, 75 wt.\%) in polypropylene as a matrix (Fig. 3). The ASTM standards D 638 for tensile tests the results are shown in Fig. 1 and Table 3 for material testing. 


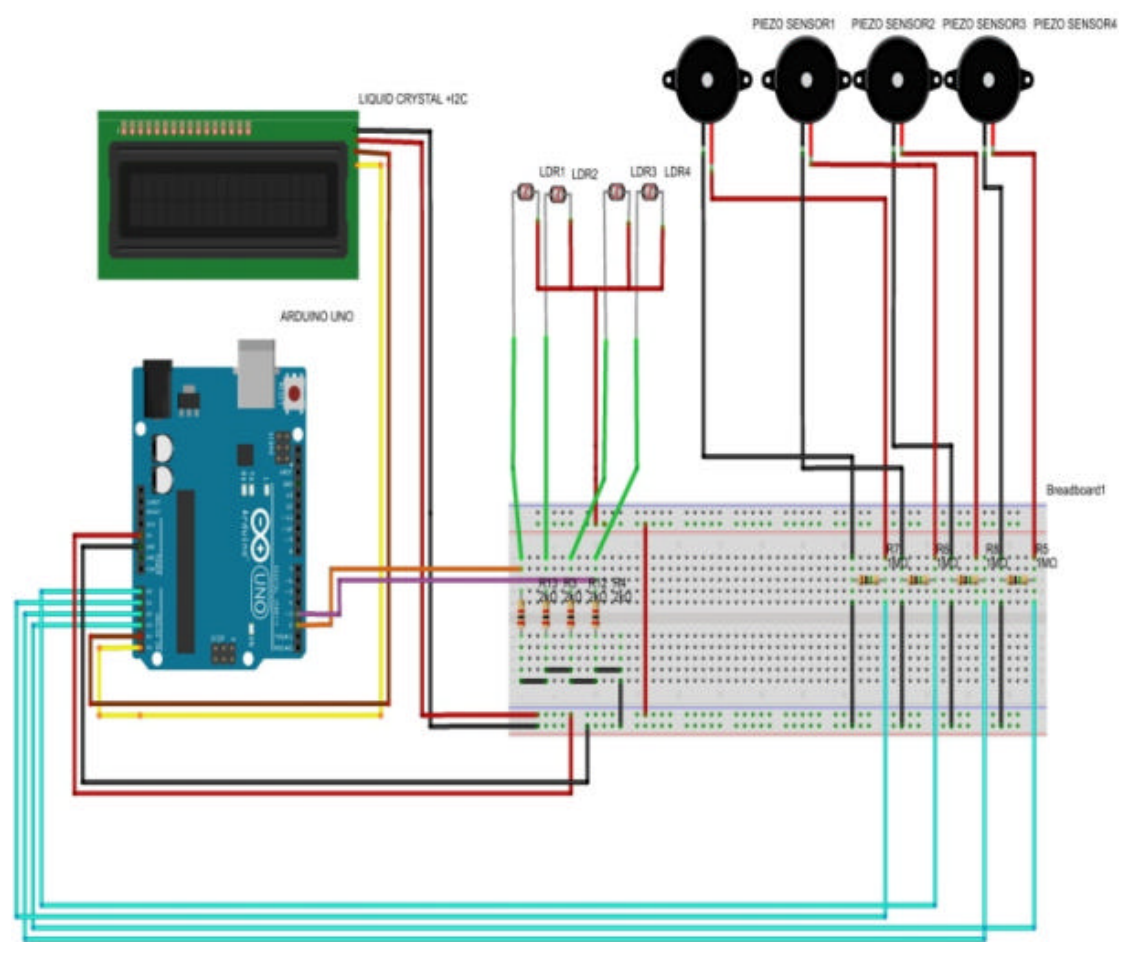

Fig. 4: Connection of piezoelectric sensor with Adruino UNO

Experimental testing system: A simple equipment is design according to the idea of experiment material test as shown in Fig. 2 and manufactured for testing and getting the necessary required parameters for calculations which seems to the single degree of freedom with excitation force which appears from the impact test. The composite material with a thin aluminum pressurized under internal pressure as a tire of car which $<100$ bar subjected to the ramp or shock during running on ununiformed road.

The study need to measure the velocity for a free drop steel ball by Light Dependent Resistor (LDR) Arduino sensors system which are connected to the Arduino hardware and read the velocity value in the LCD monitor as shown in Fig. 3a and $b$ for a vertical distance $400 \mathrm{~mm}$ with a friction from a contact with frictionless class tube which used for the insure that the vertical contact angle is $90^{\circ}$ with the surface of composite material which the deformation is measured by a digital dial gage as shown in Fig. 4 and 5. On the thin aluminum plate with and without composite materials with total thickness not more then $5 \mathrm{~mm}$. Then the system is assembled with these all required equipment for study and impact test as shown in Fig. 3d which help to record all the output resulted data for comparison in the study by connected with a computerized system.

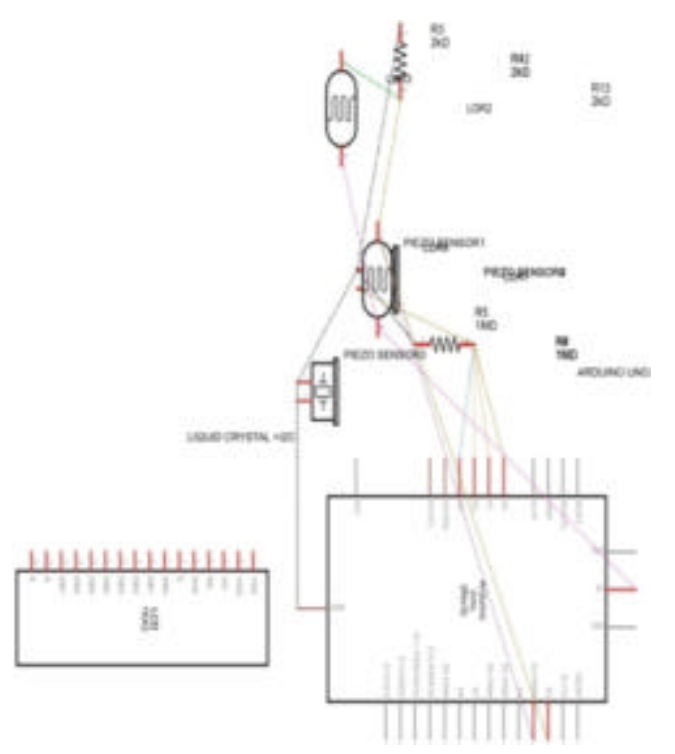

Fig. 5: Impact speed and time connection using Light Dependent Resistor (LDR) circuit connection design

\section{RESULTS AND DISCUSSION}

For the $75 \mathrm{wt} . \%$ of wood flour content with a good adhesion the results have increasing in a stiffness of the 
composites which improve the strength and the wood content in composite haven't much recognized changing in impact resistance, especially in 25 and 75 wt. $\%$ of wood content. The effect of particle size of the wood flour in the polypropylene as a matrix, for the 50, 100 and $150 \mu \mathrm{m}$ as shown in Fig. 1 that with increase in the size wood flour particles observed decreasing in modulus of elasticity and a smaller drop in elastic-impact strength because of the increase in performance-surface filling which lead to choose the $150 \mu \mathrm{m}$ with $75 \mathrm{wt} . \%$ for impact testing to get an expected acceptable results in damping ratio to avoid the continuity of vibration with a good shock absorption system (Fig. 6-8).

From Fig. 9, the experimental results agree with the theoretical results which agree with the method had don by Metz (2007) but its clear that in light weight is more

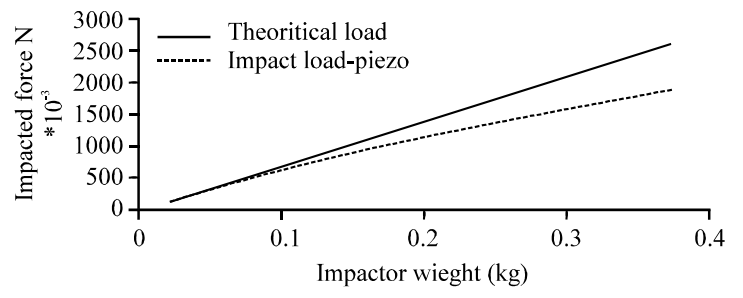

Fig. 6: Impacted load results recorded from piezoelectric sensor

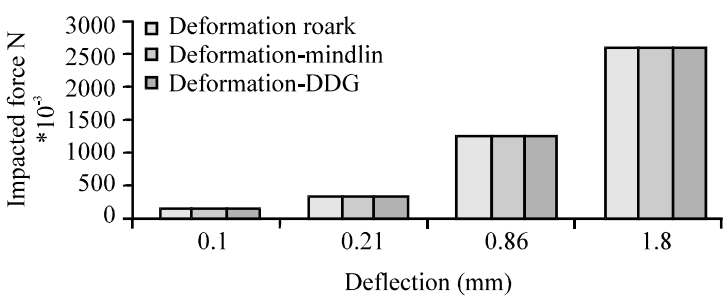

Fig. 7: Theoretically deformations results just for aluminum thin plate $0.6 \mathrm{~mm}$ with experimental deformations results by DDG sensor recorded as a bar chart

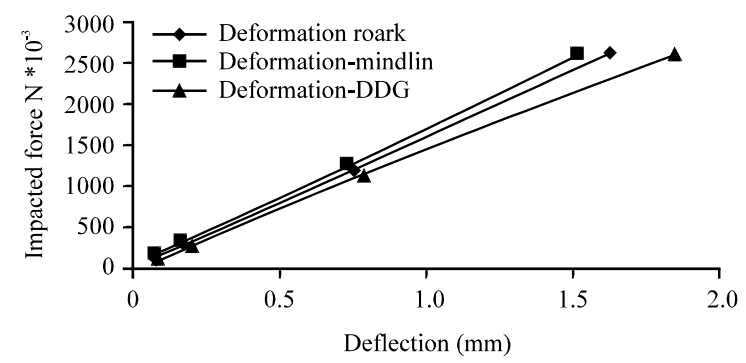

Fig. 8: Theoretical and experimental deformation with coted composite material $2 \mathrm{~mm}$ acceptable than heavy weight because of the sensitive accuracy of the piezoelectric diaphragms used in this study which is a piezoelectric ceramic disks adhered to a metal plates of brass or nickel-alloy, this commercial piezoelectric sensor dose not accurately recorded data, especially, if the impact force more than $1000 \mathrm{~N}$.

The impacted loads divided into light and heavy weight Fig. 6 which recorded as a response impacted signal from piezoelectric sensor and LDR for measuring the experimental velocity of free drop impactors steel balls. And by using Roark's formulas and Mindlin's plate theory equations and the experimental deformation results aluminum thin plate without the composite material Fig. 7 and aluminum with composite material layers until $5 \mathrm{~mm}$ as in Fig. 8-10 from the Digital Dial Gage (DDG) which are used for measurement comparison between theories. These phenomena has done because of the changing the system shock absorber by adding the air inside the thin coated plate and appears the effect of the viscous damping coefficient and the system has got the mass-spring-damper single degree of freedom (Fig. 11 and 12).

Piezoelectric sensor signal resulted from Arduino: For acceleration $7003.5 \mathrm{~m} / \mathrm{sec}^{2}$ with velocity $2.8 \mathrm{~m} / \mathrm{sec}$ with $40 \mathrm{~cm}$ height of free drop of bodies weight increasing $(0.022,0.045,0.17$ and $0.37 \mathrm{~kg})$ with decreasing

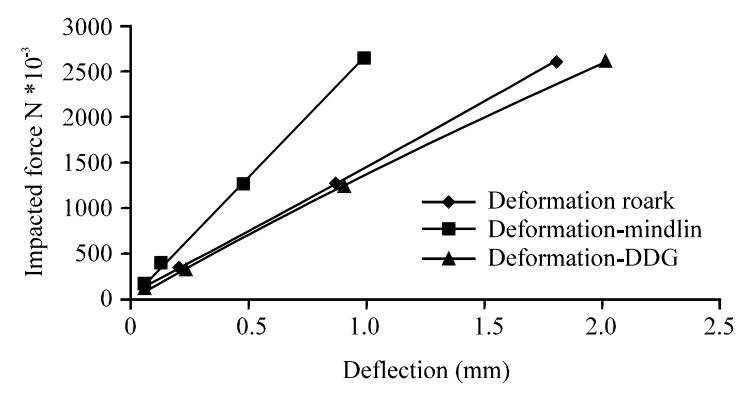

Fig. 9: Theoretical and experimental deformation with coted composite material $2.4 \mathrm{~mm}$

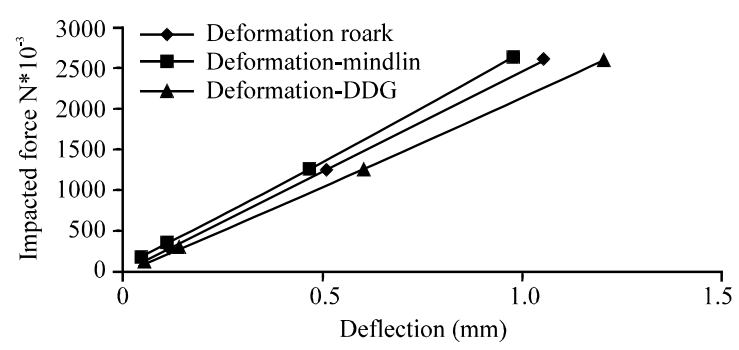

Fig. 10: Theoretical and experimental deformation with coted composite material 5-6 mm 


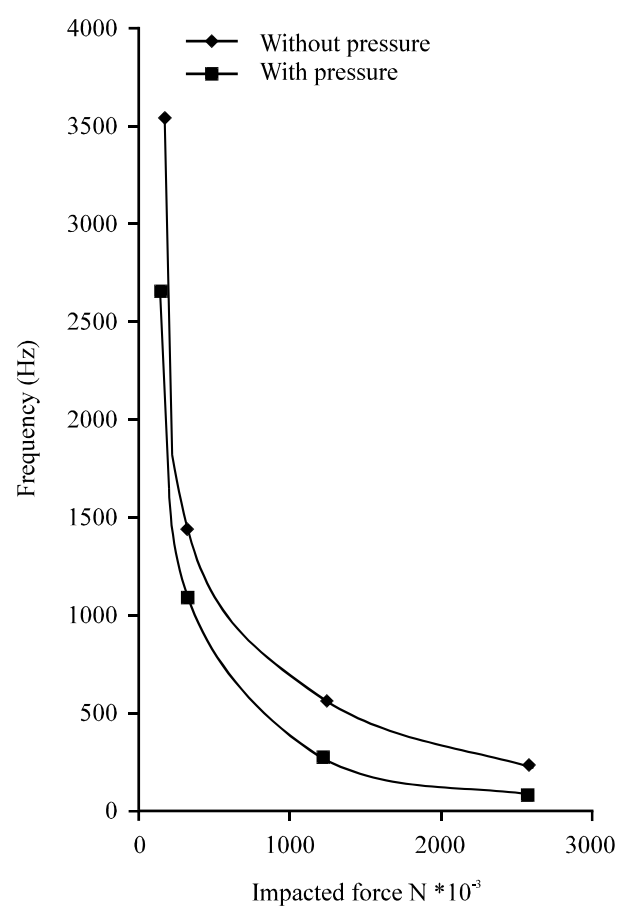

Fig. 11: Impacted force with natural frequency with and without effected internal pressure

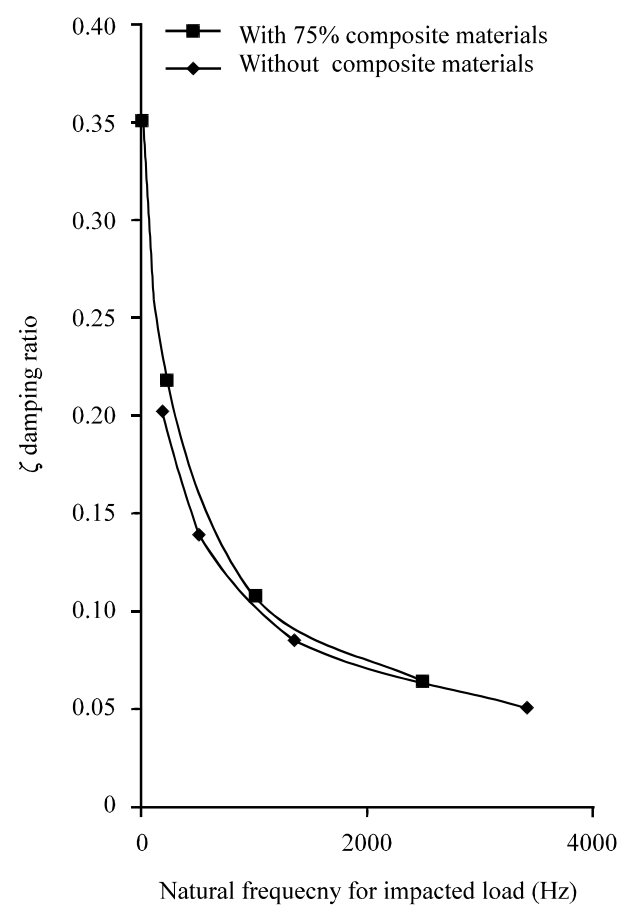

Fig. 12: Frequency impacted force with damping ratio under internal pressure and composite materials

1-0.29 msec in time of impacted contact. The resulted parameters have got from the analyzing the wave data as

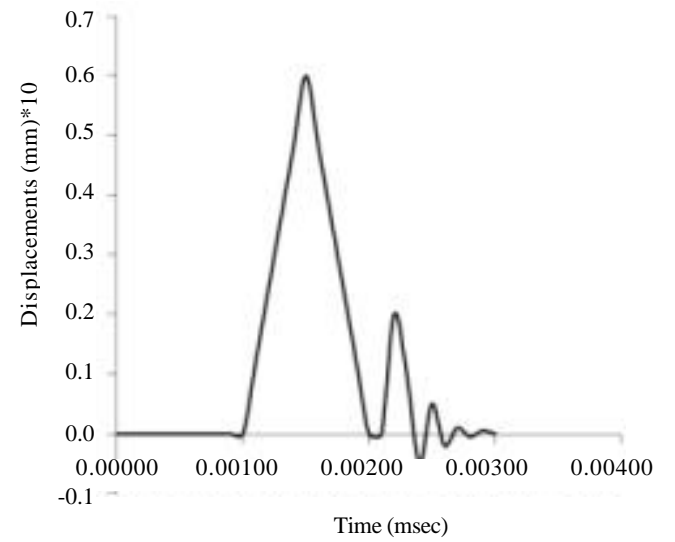

Fig. 13: Impact signal with $0.022 \mathrm{~kg}$ with impact contact time $1 \mathrm{msec}$

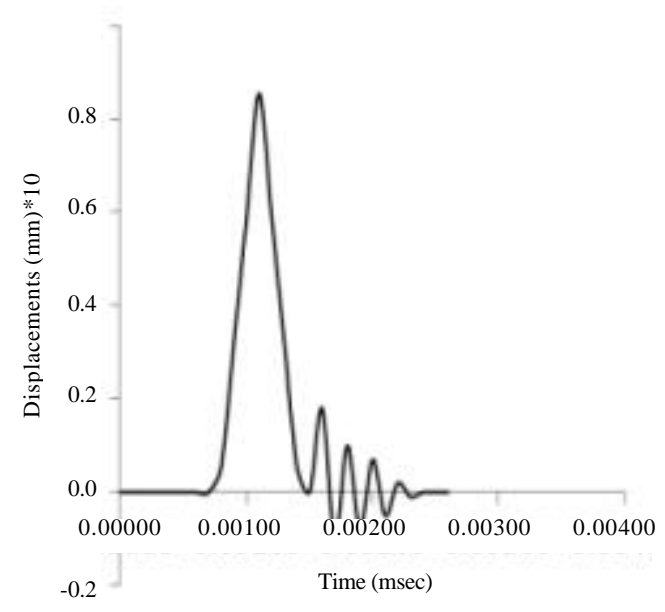

Fig. 14: Impact signal with $0.045 \mathrm{~kg}$ with impact contact time $0.6 \mathrm{msec}$

shown in Fig. 11 and 12, the impact load, natural frequencies and the damping ration after adding the internal pressures inside the coated thin aluminum plate.

Figure 13-16 with analysis of the signals produced by different impacted loads which have increasing in weight and first maximum amplitude for first impact and second and third sometime because of the additional jumping after first touch with surface on the plate. The impacted wave signal analysis from sensors analysis with Microsoft Excel shown in Fig. 13-16.

For improving the agreement of choosing the material with 75 wt.\% of a wood/polypropylene composite material with a wood flour percentage weight $(25,50$ and $75 \%$ ) and grain size $150 \mu \mathrm{m}$ under internal pressure and 


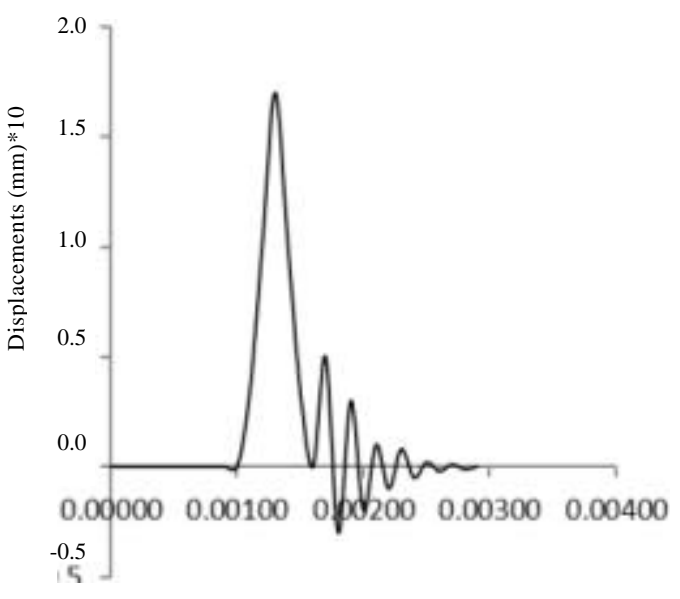

Fig. 15: Impact signal with $0.17 \mathrm{~kg}$ with impact contact time $0.52 \mathrm{msec}$

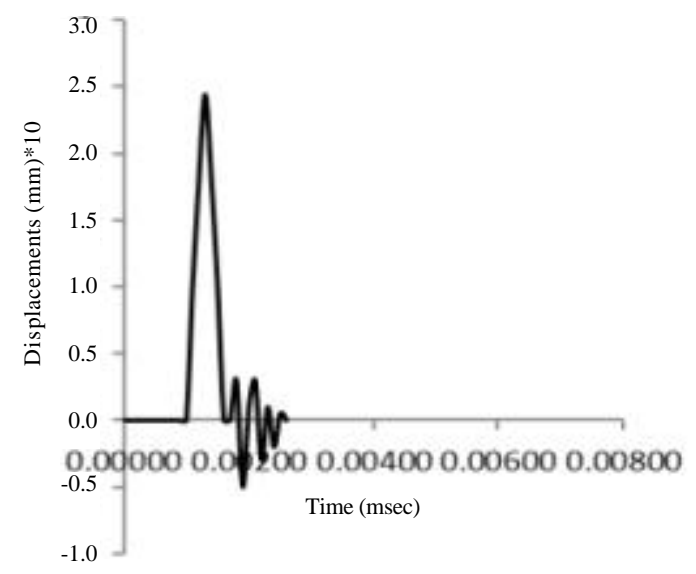

Fig. 16: Impact signal with $0.37 \mathrm{~kg}$ with impact contact time $0.29 \mathrm{msec}$

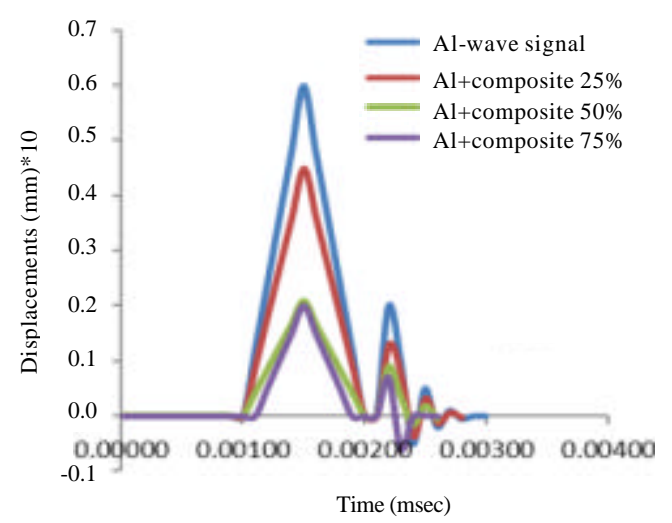

Fig. 17: Impact signal for low weight with $0.022 \mathrm{~kg}$ with impact contact time $1 \mathrm{msec}, \mathrm{AL}+$ composite $75 \%, \mathrm{E}=1.5 \mathrm{GPa}$

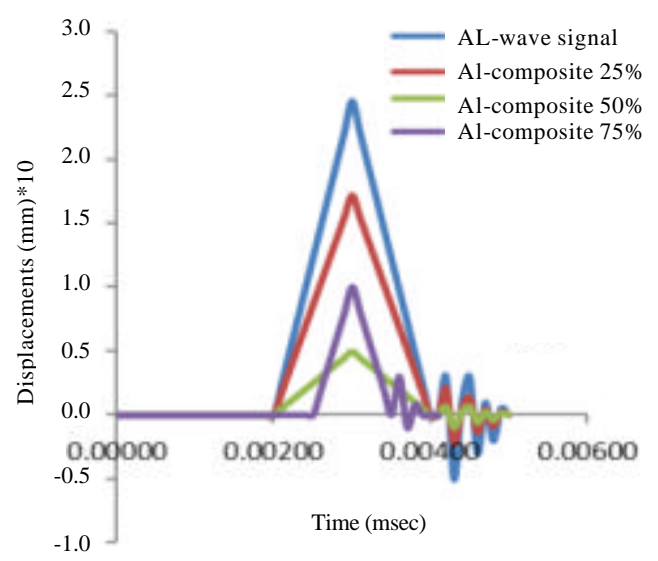

Fig. 18: Impact signal for heavy weight with $0.37 \mathrm{~kg}$ with Impact contact time $0.29 \mathrm{msec}, \mathrm{Al}+$ composite $75 \%, \mathrm{E}=1.5 \mathrm{GPa}$

impact test with low and heavy weight impacted load as shown in Fig. 17 and 18 which show the completely imagination of the all impacted signals that help to understand of the behavior of the materials which coated with different wt.\% of wood flour that is shown all signals of impacted test for low and heavy impacted load and the increasing of contacted impacted time $1 \mathrm{msec}$ in the low impacted load with low value of displacement in plate deformation.

\section{CONCLUSION}

For a clamped isotropic circular thin aluminum plate under pressure and coated with a wood flour in the polypropylene as a matrix composite material under impact analysis as a free drop bodies by using experimental and analytical method are compared and have some conclusions can be recognized:

The results in polypropylene with wood flour $75 \%$ with grain size $150 \mu \mathrm{m}$, gives a good material with an acceptable impact strength under acceptable damping ratio between $0.085-0.35$. Under these conditions this coated materials may be find a large applications in areas where reduction of vibration is necessary required in general the experimental results of deformation due to the impacted load are nearly agree with the deflection at the center of the clamped circular thin plate using Roark's formulas, more than using Mindlin plate theory.

\section{RECOMMENDATIONS}

The increasing of impacted load without any effect of the internal pressure cause decreasing in frequency with 
a good indication for the increasing in damping ratio of a small natural frequencies for impacted load but it will be more and higher with the effect of internal pressure below of the coated thin aluminum plate. It can conclude that the decreasing of impact contact with increasing of the impacted load and damping frequency, these resulted relations because of the type of composite materials had coated the thin aluminum plate and because of the shear deformation was not considered in the thin plate but if the plate was thick then the effect of shear deformation should be more considerable and effected on the results obtained.

\section{REFERENCES}

Anonymous, 2016. Basics of structural vibration testing and analysis. Crystal Instruments Inc., Santa Clara, California. https://www.crystalinstruments.com/ basics- of-structural-vibration-testing-and-analysis/

Bakir, P.G., 2004. Vibration of single degree of freedom systems. Pelin Gundea Bakir, Artvin, Turkey.

Chauhan, S., A. Karmarkar and P. Aggarwal, 2009. Damping behavior of wood filled polypropylene composites. J. Appl. Polym. Sci., 114: 2421-2426.

Gibson, R.F., 2011. Principles of Composite Material Mechanics. 3rd Edn., CRC Press, Boca Raton, Florida, USA., ISBN-13:978-1439850053, Pages: 683.

Gujar, P.S. and K.B. Ladhane, 2015. Bending analysis of simply supported and clamped circular plate. Intl. J. Civ. Eng., 2: 69-75.

Idrus, M.M., S. Hamdan, M.R. Rahman and M.S. Islam, 2011. Liquefied tropical wood/polypropylene composites: Preparation and physico-mechanical properties. Mater. Phys. Mech., 11: 126-136.

Kallakas, H., T. Poltimae, T.M. Suld, J. Kers and A. Krumme, 2015. The influence of accelerated weathering on the mechanical and physical properties of wood-plastic composites. Proc. Est. Acad. Sci., 64: 94-105.
Keledi, G., A. Sudar, C. Burgstaller, K. Renner and J. Moczo et al., 2012. Tensile and impact properties of three-component PP/wood/elastomer composites. Exp. Polym. Lett., 6: 224-236.

Metz, R., 2007. Impact and Drop Testing with ICP Force Sensors. PCB Piezotronics, Inc., Depew, New York, USA.

Mohammed, A.A., 2015. Investigation of tensile and impact of composite materials reinforced with natural materials. Eng. Technol. J., 33: 919-933.

Mohammed, R.H. and M.M. Hanoos, 2017. The effect of nanoparticles additives on impact strength of metal matrix composites. Eng. Technol. J., 35: 37-40.

Peraire, J. and S. Widnall, 2003. Lecture L9-Linear Impulse and Momentum, Collisions. In: Engineering Mechanics: Dynamics, Meriam, J.L. and L.G. Kraige (Eds.). Wiley Publishing Company, Hoboken, New Jersey, USA., ISBN:9780471266068, pp: 1-13.

Salih, S.E., J.K. Oleiwi and R.A.A. Ameer, 2015. Comparing effect of adding LDPE, PP, PMMA on the mechanical properties of polystyrene (PS). Eng. Technol. J., 33: 1450-1461.

Tremaine, K.M., 2012. Modal analysis of composite structures with damping material. Master Thesis, California Polytechnic State University, San Luis Obispo, California, USA.

Verros, G., S. Natsiavas and C. Papadimitriou, 2005. Design optimization of quarter-car models with passive and semi-active suspensions under random road excitation. Mod. Anal., 11: 581-606.

Young, W. and R. Budynas, 2002. Roark's Formulas for Stress and Strain. 7th Edn., McGraw-Hill, New York, ISBN-13:978-0070725423, Pages: 832. 